\title{
Additive-free synthesis of mesoporous FAU-type zeolite with intergrown structure
}

\author{
Xiaoli Jia ${ }^{1}$ Lu Han ${ }^{1}$, Yanhang $\mathrm{Ma}^{2}$ and Shunai Che ${ }^{1^{*}}$
}

\begin{abstract}
Hierarchical porous zeolites attract great attention because of their porosity on different scales to improve molecular diffusion. Here, we report mesoporous Faujasite (FAU) zeolite nanosheets with intergrown structure synthesized in an additive-free system. The sample was composed of uniform nanosheets with a slice thickness of $\sim 50 \mathrm{~nm}$, which held a honeycomb-like structure with abundant mesopores. This material exhibits both microporous and mesoporous structure: the intrinsic micropores with a diameter about $0.74 \mathrm{~nm}$ in the zeolite framework and the mesopores with a diameter about $10 \mathrm{~nm}$ existing within the zeolite nanosheets. The Si/Al ratios can be adjusted from 1.1 to 1.9 (zeolites $\mathrm{X}$ or $\mathrm{Y})$. In addition, this simple and environment-friendly method may provide inspiration to the synthesis of other hierarchical zeolites.
\end{abstract}

Keywords: mesoporous zeolite, additive-free synthesis, intergrown structure

\section{INTRODUCTION}

Zeolites, crystalline microporous materials with pores and channels in molecular scale, are of great importance for industrial application [1-4]. However, the single micropore usually limits the molecule diffusion and fails to catalyze organic molecules in large dimensions. This problem can be solved by shortening effective diffusion path lengths [5-7], which has been achieved by miniaturizing zeolite crystals, delaminating or exfoliating layered zeolites, and introducing mesopores into zeolite particles [8]. Among these solutions, hierarchical zeolites combine intrinsic micropores and bypass-interconnected mesopores and therefore, enhance the micropore accessibility and molecular traffic within zeolite particles.

Hierarchical zeolites show an enhanced accessibility of the active framework for the reactants with different molecular dimensions compared to conventional zeolites. Therefore, a lot of strategies including top-down desilication by alkali treatment [9-11], and bottom-up directed by hard [12-17] and soft template [18-34] have been proposed to synthesize meso-micro or macro-meso-micro zeolites. However, desilication is not suitable for the zeolite at low $\mathrm{Si} / \mathrm{Al}$ molar ratio such as FAU, LTA, etc. Hard template method requires multistep procedures and is not favorable for large scale production. Alternatively, soft-template method is a simple and universal strategy to synthesize mesoporous zeolites.

FAU-type zeolite, a highly hydrophilic large-pore zeolite with a pore diameter of $0.74 \mathrm{~nm}$ at a low Si/Al molar ratio, is widely used in separation process (zeolite $\mathrm{X}$ ) and catalytic conversion (zeolite Y). There are a few reports about the creation of additional porosity by soft template method [35-38], such as organosilane surfactants, ionic liquid and so on. For example, 3-(trimethoxysilyl)propyl hexadecyl dimethyl ammonium chloride (TPHAC) was used as surfactant to synthesize mesoporous FAU-type zeolite nanosheets with intergrown structure. The hierarchically branched FAU with house-of-cards like morphology contains three pore systems: the micropores in FAU framework, mesopores in the nanosheets and macropores interstices between the nanosheet stacks. However, this method holds another drawback that organic-template is not environmentally friendly, and they are non-recyclable and expensive. Furthermore, hierarchical FAU zeolites synthesized by soft-template method usually holds low $\mathrm{Si} / \mathrm{Al}$ ratio $(<1.5)$, which caused relative low thermal stability. Therefore, the synthesis of hierarchical FAU zeolite with high thermal stability through a cheap way is particular important for industrial application.

Herein, we report an approach to synthesize hier-

${ }^{1}$ School of Chemistry and Chemical Engineering, State Key Laboratory of Metal Matrix Composites, Shanghai Jiao Tong University, Shanghai 200240, China

${ }^{2}$ School of Physical Science and Technology, ShanghaiTech University, Shanghai 201210, China

*Corresponding author (email: chesa@sjtu.edu.cn) 


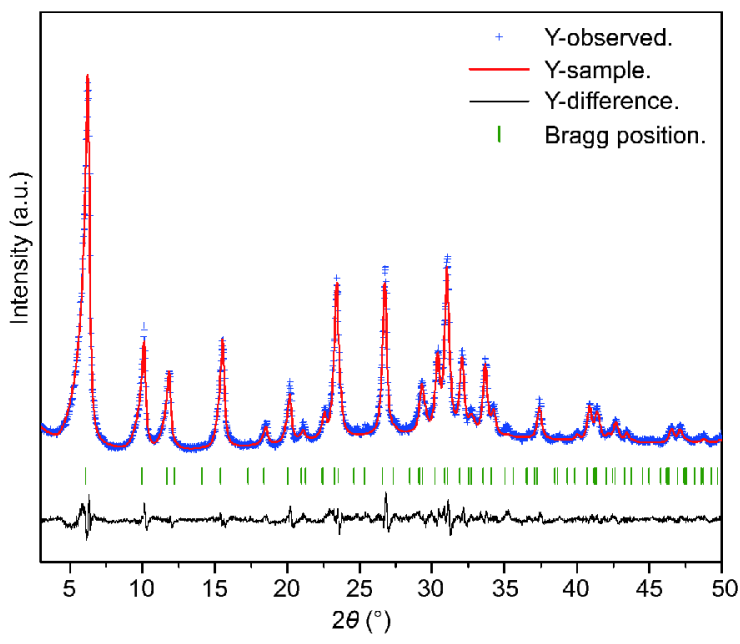

Figure 1 XRD patterns of the as-made mesoporous FAU zeolite crystallized at $60^{\circ} \mathrm{C}$ for $24 \mathrm{~h}$. Vertical ticks correspond to line indexing of the FAU phase. Difference plots between calculated and experimental points are shown at the bottom. The synthesis molar composition was $1 \mathrm{SiO}_{2}$ : $0.2 \mathrm{Al}_{2} \mathrm{O}_{3}: 4.5 \mathrm{Na}_{2} \mathrm{O}: 180 \mathrm{H}_{2} \mathrm{O}$.

archical FAU zeolite by sequential intergrowth without any organic or inorganic additions. The selection of optimized synthesis conditions that can form interlaced nanosheets seems to be a key to achieving hierarchical structure. We particularly focuse on the FAU zeolite because it is widely used in industrial process due to its 12ring in the framework and high thermal stability. To our knowledge, the synthesis of FAU zeolites with hierarchical structure and adjustable $\mathrm{Si} / \mathrm{Al}$ ratio under no template has not been reported before. We hope our environmentally and low-cost approach to create mesopores in zeolite can provide help for industrial production.

\section{EXPERIMENTAL SECTION}

\section{Synthesis of zeolite materials}

In a typical synthesis of FAU zeolites, $7 \mathrm{~g}$ sodium hydroxide (AR, solid) was first dissolved in water and then the solution was divided into two parts. $7.1 \mathrm{~g} \mathrm{Na}_{2} \mathrm{SiO}_{3}$. $9 \mathrm{H}_{2} \mathrm{O}$ (AR, solid) was added to one part and $0.82 \mathrm{~g}$ sodium aluminate $(96 \%$, solid) was added to another, the two solutions were mixed and stirred for $5 \mathrm{~h}$ in an ice bath. Then the mixture with the composition of $1 \mathrm{SiO}_{2}$. $0.2 \mathrm{Al}_{2} \mathrm{O}_{3}: 4.5 \mathrm{Na}_{2} \mathrm{O}: 180 \mathrm{H}_{2} \mathrm{O}$ was transferred into Teflon autoclaves in a static environment at $60^{\circ} \mathrm{C}$. After a crystallization period, the final products were filtered, washed with distilled water and dried at $60^{\circ} \mathrm{C}$ overnight.

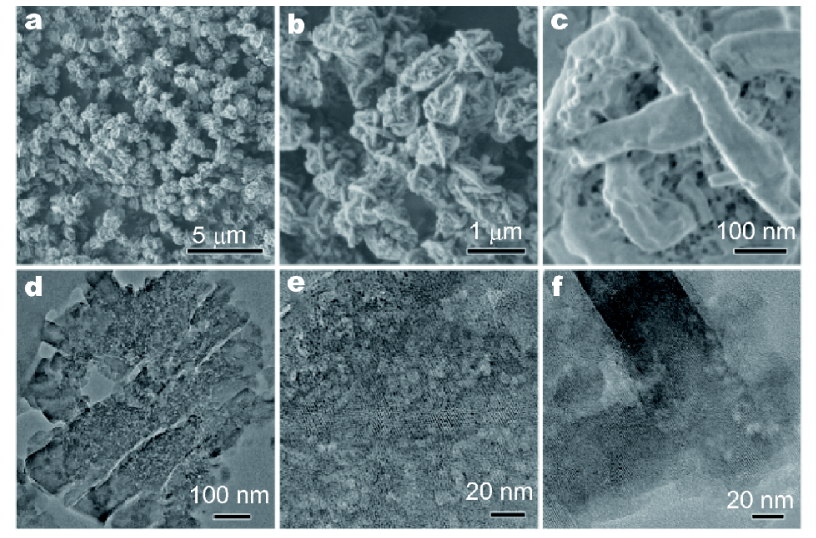

Figure 2 SEM $(a-c)$ and TEM images $(d-f)$ taken at different magnifications of the sample shown in Fig. 1.

\section{Characterizations}

Powder X-ray diffraction (XRD) patterns were recorded on a Rigaku X-ray diffractometer D/max-IIIA equipped with $\mathrm{Cu} \mathrm{Ka}$ radiation $(40 \mathrm{kV}, 30 \mathrm{~mA})$. SEM was conducted on a JEOL JSM-7401F electron microscope operated at $1 \mathrm{kV}$ and JEOL JSM-7800F electron microscope operated at $0.3 \mathrm{kV}$. HRTEM was performed using JEOL JEM-2100 microscope operating at $200 \mathrm{kV}$ (Cs $=1.4 \mathrm{~mm}$, point resolution of $2.3 \AA$ ). The nitrogen adsorption/desorption isotherms were measured at $77 \mathrm{~K}$ using an ASAP $2010 \mathrm{M}+\mathrm{C}$ analyzer after the samples were degassing at $150^{\circ} \mathrm{C}$ for $12 \mathrm{~h}$. For element analysis, the samples were first dissolved in hydrofluoric acid (50\% in water) and nitrohydrochloric acid solution, then steaming on the electric heating plate. Finally, the dried sample was extracted by dilute nitrohydrochloric acid. The element analysis of $\mathrm{Si}, \mathrm{Al}$ and $\mathrm{Na}$ was determined from the inductively coupled plasma analysis (ICP, Perkin-Elmer 3300DV) and Elementar Vario-ELIII IRMS analyzer.

\section{RESULTS AND DISCUSSION}

The hierarchical FAU zeolite was crystallized at $60^{\circ} \mathrm{C}$ for $24 \mathrm{~h}$ without any additives. The wide-angle X-ray diffraction (XRD) patterns of the samples shown in Fig. 1 verify that high-quality FAU zeolite was obtained, as the competing crystalline phases such as zeolite LTA and zeolite $\mathrm{P}$ were not observed. The phase purity was also identified by corresponding SEM images (Fig. $2 \mathrm{a}-\mathrm{c}$ ). The $\mathrm{Si} / \mathrm{Al}$ molar ratio was 1.1 , which is in the range of $1.0-1.5$ for FAU-type zeolite X.

The representative SEM images (Fig. 2a-c) of hierarchical FAU zeolites show that the sample exhibits a uniform flower-like morphology with an average size of about $1 \mu \mathrm{m}$. The flower-like particles are composed of 

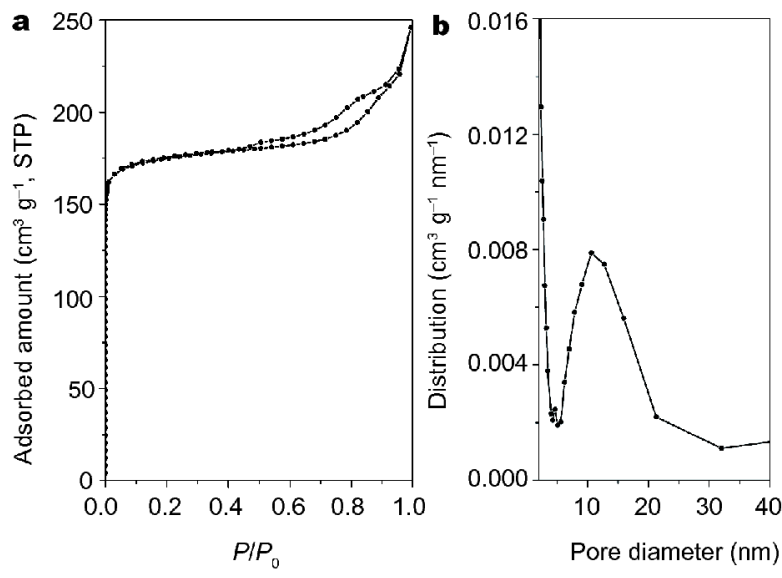

Figure 3 Nitrogen physisorption isotherms (a) and pore size distribution (b) of mesoporous FAU zeolites shown in Fig. 1.

nanosheets with a slice thickness of $\sim 50 \mathrm{~nm}$ with a honeylike structure, which was further confirmed by the TEM images (Fig. 2e, f). The intergrowth between two nanosheets is clearly shown in Fig. 2c. Fig. 2e, f show TEM images of sliced thin section of the as-prepared sample. The low-magnification TEM image (Fig. 2d) shows the inner layer was constituted by honeycomb structure and the outer layer was single crystal. HRTEM image (Fig. 2e) shows abundant mesopores with an average diameter of $\sim 10 \mathrm{~nm}$ in the nanosheets.

The microporous and mesoporous structure of hierarchical FAU zeolites was measured by nitrogen sorption analysis (Fig. 3). The adsorption-desorption isotherms that exhibit a steep increase below $P / P_{0}=0.02$ is the characteristic of microporous materials. As expected, a hysteresis loop at the relative pressure $P / P_{0}$ of $0.4-0.8$ indicates the presence of mesopores. The zeolitic nanosheets characteristic of microporous materials. As expected, a hysteresis loop at the relative pressure $P / P_{0}$ of $0.4-0.8$ indicates the presence of mesopores. The zeolitic nanosheets exhibits mesopores in a diameter of around $10 \mathrm{~nm}$ according to the pore size distribution curve, which is in accordance with TEM. A high BrunauerEmmett-Teller (BET) surface area of $544 \mathrm{~m}^{2} \mathrm{~g}^{-1}$ and Langmuir surface area of $850 \mathrm{~m}^{2} \mathrm{~g}^{-1}$ and a total pore volume of $0.39 \mathrm{~cm}^{3} \mathrm{~g}^{-1}$ were calculated with the meso- and micropore volume being $0.13 \mathrm{~cm}^{3} \mathrm{~g}^{-1}$ and $0.26 \mathrm{~cm}^{3} \mathrm{~g}^{-1}$, respectively.

The synthesis condition and the composition greatly affect the structure of the zeolite. The key factor in the synthesis of mesoporous FAU zeolite in this additive-free system is the precise control of the aging temperature, $\mathrm{Si} / \mathrm{Al}$ and $\mathrm{OH}^{-} / \mathrm{Si}$. We carefully investigated the compo- sition change, while keeping other factors constant to achieve the full synthesis conditions.

The XRD patterns and the SEM images (Fig. S1) show that amorphous aluminosilicate was obtained at the low aging temperature of $40^{\circ} \mathrm{C}$, as the low intensity of the XRD pattern and the amorphous phase in the SEM image. Very weak peaks of FAU appear when the aging temperature was $50^{\circ} \mathrm{C}$, indicating the lower crystallinity. Relatively high crystalline FAU zeolite was obtained when the aging temperature was $60^{\circ} \mathrm{C}$ and the sample holds a flower-like morphology. When the temperature was increased to higher than $60^{\circ} \mathrm{C}$, bulk FAU zeolites were synthesized (Fig. S1e, f). The formation of a zeolite with poor crystallinity at low temperature and bulk structure at high temperature are both unfavorable for the catalytic reaction including bulk molecules. Therefore, the temperature of $60^{\circ} \mathrm{C}$ was considered to be the most appropriate to direct the mesoporous FAU zeolites.

In order to study the effect of the $\mathrm{Si} / \mathrm{Al}$ molar ratios on the formation of mesoporous FAU zeolite, the synthesis was carried out with different molar ratios of $\mathrm{Si} / \mathrm{Al}$ at $60^{\circ} \mathrm{C}$ for $24 \mathrm{~h}$. As FAU-type zeolite is a kind of aluminum-rich microporous zeolite, we adjusted the $\mathrm{Si} / \mathrm{Al}$ ratio from 1 to 4 (Figs S2, S3). The XRD patterns clearly show that low $\mathrm{Si} / \mathrm{Al}$ ratio results in the impure phase of LTA, the typical cubic morphology can be observed from the SEM images (Fig. S3a, b). Although ratios of $\mathrm{Si} / \mathrm{Al}$ above 3 can produce pure FAU zeolite, all the samples show bulk morphology (Fig. S3e, f). From our results, the mesoporous FAU zeolite can only be synthesized under the synthetic gels with ratios of Si/Al between 2 to 3 . Furthermore, we investigated the influence factor of the $\mathrm{OH}^{-} / \mathrm{Si}$ molar ratios (Figs S4, S5). Low $\mathrm{OH}^{-} / \mathrm{Si}$ molar resulted in amorphous phase, while high $\mathrm{OH}^{-} / \mathrm{Si}$ molar resulted impure phase. The $\mathrm{OH}^{-} / \mathrm{Si}$ molar between 7 to 9 could direct FAU zeolite without any other phase, the morphology changed from bulk to flower-like structure.

To investigate the formation process of mesoporous FAU zeolite in this template-free system, several samples were collected during the synthesis procedure. Fig. 4 shows the XRD patterns of the representative samples at different crystallization times. The sample collected at $6 \mathrm{~h}$ exhibits a broad peak that suggests an amorphous structure. The sample was partially crystallized when aging time increased to $12 \mathrm{~h}$ as the representative diffraction peaks appeared. The stronger diffraction peaks of FAU zeolite at $24 \mathrm{~h}$ indicated that high quality of FAU zeolite was obtained. As the crystallization time increases, the crystal structure remains unchanged, suggesting the relative high thermal stability. 


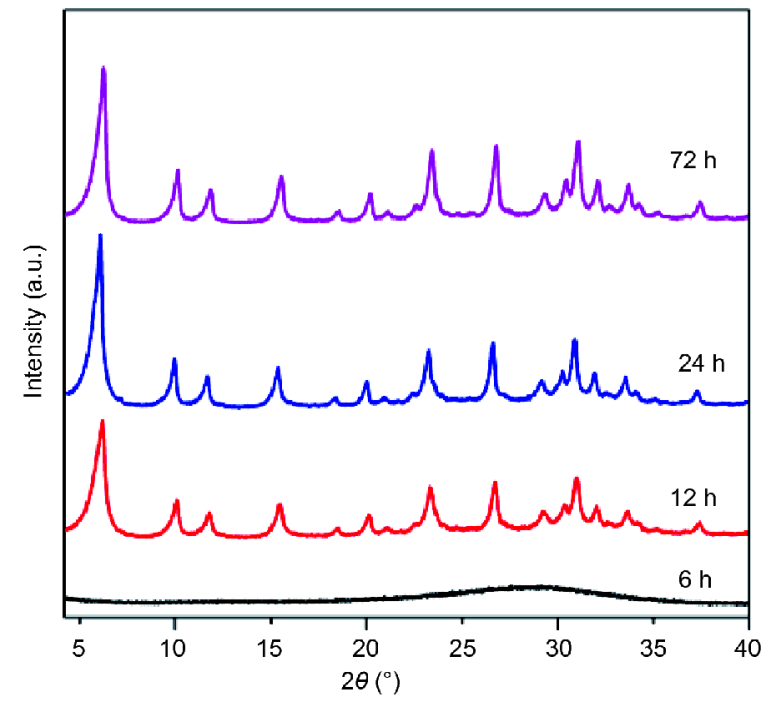

Figure 4 XRD patterns of the as-made mesoporous FAU zeolite for various aging times at $60^{\circ} \mathrm{C}$. The synthesis molar composition was $4.5 \mathrm{Na}_{2} \mathrm{O}: 0.2 \mathrm{Al}_{2} \mathrm{O}_{3}: 1 \mathrm{SiO}_{2}: 180 \mathrm{H}_{2} \mathrm{O}$.

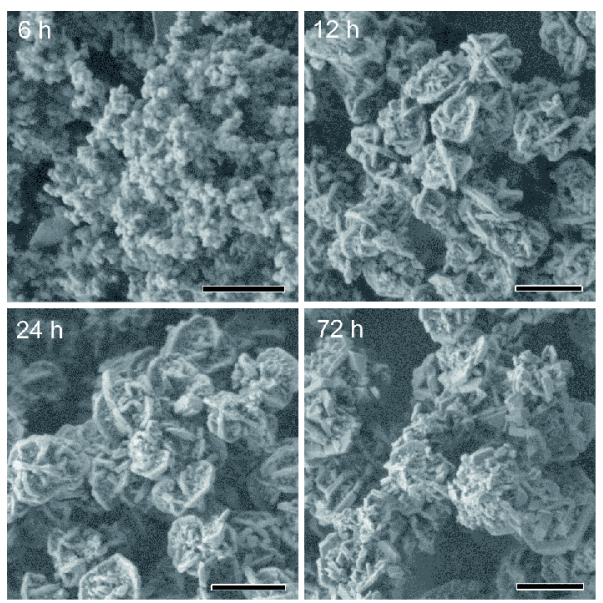

Figure 5 SEM images of the as-made hierarchical FAU zeolite. The scale bar in the SEM images was $1 \mu \mathrm{m}$.

The SEM image (Fig. 5) show the amorphous structure possesses a spherical-like morphology. The flower-like morphology was formed with the prolonging of the crystallization time to $12 \mathrm{~h}$ and the morphology remained unchanged when the crystalline time was extended to $24 \mathrm{~h}$. All the samples show hierarchical structure according to the nitrogen physisorption isotherms and pore size distribution (Fig. 6). However, the meospore surface area and volume decrease when the aging time is $72 \mathrm{~h}$ while the micropore textures remain the same (Table S1) because of the Ostwald ripening.
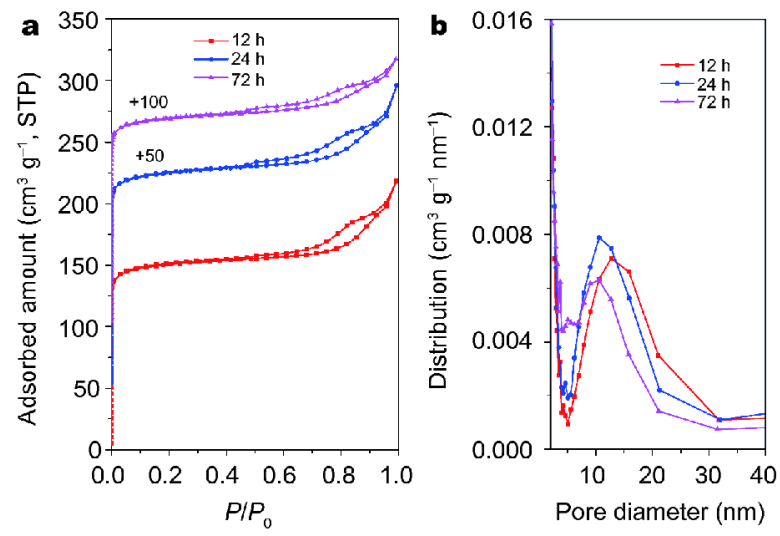

Figure 6 Nitrogen physisorption isotherms (a) and pore size distribution (b) of mesoporous FAU zeolites.

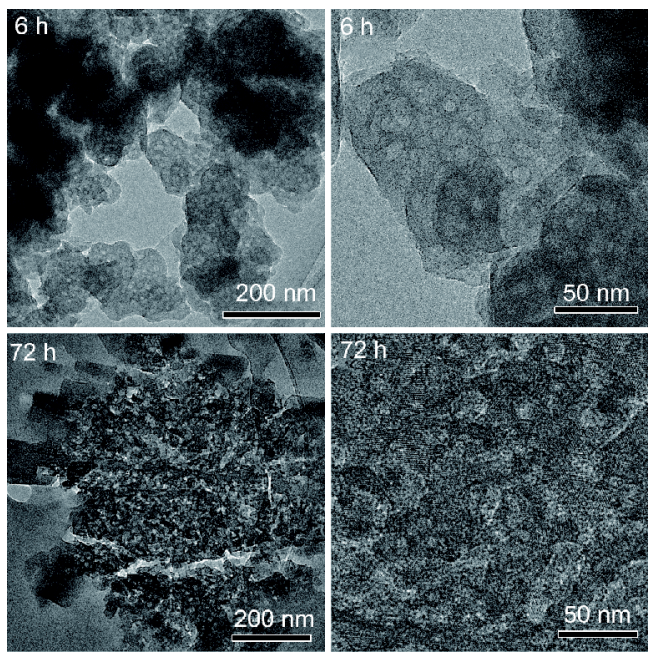

Figure 7 TEM images of the as-made mesoporous FAU zeolite.

The TEM images of the sample collected at $6 \mathrm{~h}$ and $72 \mathrm{~h}$ were taken (Fig. 7), it is obvious that the amorphous sphere exhibits hollow structure. We speculated the mechanism of the formation of mesoporous FAU zeolites according to the crystal growth process. The both existence of crystallization and desolution-recrystallization due to the high alkalinity in the synthesis system would cause the central hole. The initial amorphous aluminosilicate would be gradually turned into crystalline phase while the mesoporous structure remained with the extension of aging time. Furthermore, the relatively lower crystalline temperature weakened the effect of Ostwald ripening, which avoids the formation of bulky structure. However, the condensation of the silicon oxygen bond caused dense skeletal density which led to the shrinkage of mesopores during the crystallization process. There- 
fore, the final mesoporous FAU zeolite with intergrown structure was formed. Furthermore, Si/Al molar ratio could be adjusted from 1.1 to 1.9 (Table S2) by changing the composition of the reactants.

\section{CONCLUSIONS}

Mesoporous FAU zeolites with intergrown structure were successfully synthesized under a mild condition without any organic or inorganic additives. Compared to the FAU nanosheets templated by TPHAC or other organic templates, the sample obtained by this method has a high $\mathrm{Si} / \mathrm{Al}$ molar ratio, meaning higher thermal stability. Additionally, the additive-free system is low-cost and experimentally friendly, which possess great potential application value in industry. We hope our approach will provide more options and insight into the prospective synthesis of hierarchically zeolites with different framework type.

\section{Received 14 November 2017; accepted 03 February 2018;} published online 10 February 2018

1 Corma A. From microporous to mesoporous molecular sieve materials and their use in catalysis. Chem Rev, 1997, 97: 2373-2420

2 Davis ME. Ordered porous materials for emerging applications. Nature, 2002, 417: 813-821

3 Hartmann M. Hierarchical zeolites: a proven strategy to combine shape selectivity with efficient mass transport. Angew Chem Int Ed, 2004, 43: 5880-5882

4 Ali IO, El-Sheikh SM, Salama TM, et al. Controllable synthesis of $\mathrm{NaP}$ zeolite and its application in calcium adsorption. Sci China Mater, 2015, 58: 621-633

5 Corma A, Fornes V, Pergher SB, et al. Delaminated zeolite precursors as selective acidic catalysts. Nature, 1998, 396: 353-356

6 Maheshwari S, Jordan E, Kumar S, et al. Layer structure preservation during swelling, pillaring, and exfoliation of a zeolite precursor. J Am Chem Soc, 2008, 130: 1507-1516

7 Tosheva L, Valtchev VP. Nanozeolites: synthesis, crystallization mechanism, and applications. Chem Mater, 2005, 17: 2494-2513

8 Verboekend D, Mitchell S, Milina M, et al. Full compositional flexibility in the preparation of mesoporous MFI zeolites by desilication. J Phys Chem C, 2011, 115: 14193-14203

9 Mei C, Liu Z, Wen P, et al. Regular HZSM-5 microboxes prepared via a mild alkaline treatment. J Mater Chem, 2008, 18: 3496

10 Wang Y, Lin M, Tuel A. Hollow TS-1 crystals formed via a dissolution-recrystallization process. Microporous Mesoporous Mater, 2007, 102: 80-85

11 Wang Y, Tuel A. Nanoporous zeolite single crystals: ZSM-5 nanoboxes with uniform intracrystalline hollow structures. Microporous Mesoporous Mater, 2008, 113: 286-295

12 Jacobsen CJH, Madsen C, Houzvicka J, et al. Mesoporous zeolite single crystals. J Am Chem Soc, 2000, 122: 7116-7117

13 Kresge CT, Leonowicz ME, Roth WJ, et al. Ordered mesoporous molecular sieves synthesized by a liquid-crystal template mechanism. Nature, 1992, 359: 710-712

14 Wei X, Smirniotis PG. Synthesis and characterization of meso- porous ZSM-12 by using carbon particles. Microporous Mesoporous Mater, 2006, 89: 170-178

15 Schmidt I, Boisen A, Gustavsson E, et al. Carbon nanotube templated growth of mesoporous zeolite single crystals. Chem Mater, 2001, 13: 4416-4418

16 Yang ZX, Xia YD, Mokaya R. Zeolite ZSM-5 with unique supermicropores synthesized using mesoporous carbon as a template. Adv Mater, 2004, 16: 727-732

17 Janssen AH, Schmidt I, Jacobsen CJH, et al. Exploratory study of mesopore templating with carbon during zeolite synthesis. Microporous Mesoporous Mater, 2003, 65: 59-75

18 Xiao FS, Wang L, Yin C, et al. Catalytic properties of hierarchical mesoporous zeolites templated with a mixture of small organic ammonium salts and mesoscale cationic polymers. Angew Chem Int Ed, 2006, 45: 3090-3093

19 Wang L, Zhang Z, Yin C, et al. Hierarchical mesoporous zeolites with controllable mesoporosity templated from cationic polymers. Microporous Mesoporous Mater, 2010, 131: 58-67

20 Choi M, Cho HS, Srivastava R, et al. Amphiphilic organosilanedirected synthesis of crystalline zeolite with tunable mesoporosity. Nat Mater, 2006, 5: 718-723

21 Choi M, Srivastava R, Ryoo R. Organosilane surfactant-directed synthesis of mesoporous aluminophosphates constructed with crystalline microporous frameworks. Chem Commun, 2006, 103: 4380

22 Srivastava R, Choi M, Ryoo R. Mesoporous materials with zeolite framework: remarkable effect of the hierarchical structure for retardation of catalyst deactivation. Chem Commun, 2006, 103: 4489

23 Shanbhag GV, Choi M, Kim J, et al. Mesoporous sodalite: A novel, stable solid catalyst for base-catalyzed organic transformations. J Catal, 2009, 264: 88-92

24 Cho K, Cho HS, de Menorval LC, et al. Generation of mesoporosity in LTA zeolites by organosilane surfactant for rapid molecular transport in catalytic application. Chem Mater, 2009, 21: 5664-5673

25 Wang H, Pinnavaia TJ. MFI zeolite with small and uniform intracrystal mesopores. Angew Chem Int Ed, 2006, 45: 7603-7606

26 Yue MB, Sun LB, Zhuang TT, et al. Directly transforming assynthesized MCM-41 to mesoporous MFI zeolite. J Mater Chem, 2008, 18: 2044-2050

27 Choi M, Na K, Kim J, et al. Stable single-unit-cell nanosheets of zeolite MFI as active and long-lived catalysts. Nature, 2009, 461: 246-249

28 Na K, Jo C, Kim J, et al. Directing zeolite structures into hierarchically nanoporous architectures. Science, 2011, 333: 328-332

29 Singh BK, Xu D, Han L, et al. Synthesis of single-crystalline mesoporous ZSM-5 with three-dimensional pores via the self-assembly of a designed triply branched cationic surfactant. Chem Mater, 2014, 26: 7183-7188

$30 \mathrm{Xu} \mathrm{D}$, Jing Z, Cao F, et al. Surfactants with aromatic-group tail and single quaternary ammonium head for directing single-crystalline mesostructured zeolite nanosheets. Chem Mater, 2014, 26: 46124619

$31 \mathrm{Xu} \mathrm{D}, \mathrm{Ma} \mathrm{Y}$, Jing Z, et al. $\pi-\pi$ Interaction of aromatic groups in amphiphilic molecules directing for single-crystalline mesostructured zeolite nanosheets. Nat Commun, 2014, 5: 4262

32 Zhang X, Liu D, Xu D, et al. Synthesis of self-pillared zeolite nanosheets by repetitive branching. Science, 2012, 336: 1684-1687

33 Xu D, Swindlehurst GR, Wu $\mathrm{H}$, et al. On the synthesis and adsorption properties of single-unit-cell hierarchical zeolites made by 
rotational intergrowths. Adv Funct Mater, 2014, 24: 201-208

34 Chaikittisilp W, Suzuki Y, Mukti RR, et al. Formation of hierarchically organized zeolites by sequential intergrowth. Angew Chem Int Ed, 2013, 52: 3355-3359

35 Sachse A, Wuttke C, Díaz U, et al. Mesoporous Y zeolite through ionic liquid based surfactant templating. Microporous Mesoporous Mater, 2015, 217: 81-86

36 Inayat A, Knoke I, Spiecker E, et al. Assemblies of mesoporous FAU-type zeolite nanosheets. Angew Chem Int Ed, 2012, 51: 19621965

37 Khaleel M, Wagner AJ, Mkhoyan KA, et al. On the rotational intergrowth of hierarchical FAU/EMT zeolites. Angew Chem Int Ed, 2014, 53: 9456-9461

38 Inayat A, Schneider C, Schwieger W. Organic-free synthesis of layer-like FAU-type zeolites. Chem Commun, 2015, 51: 279-281
Acknowledgements This work was supported by the National Natural Science Foundation of China (21533002 and 21571128) and the National Excellent Doctoral Dissertation of China (201454).

Author contributions Che $\mathrm{S}$ designed the experiment and led the project. Jia X synthesized the mesoporous FAU zeolites and performed the SEM, XRD, $\mathrm{N}_{2}$ adsorption-desorption measurements. Jia $\mathrm{X}$ wrote the paper with support from Che S, Lu H and Ma Y. All authors contributed to the general discussions.

Conflict of interest The authors declare that they have no conflict of interest.

Supplementary information online version of the paper.
Supporting data are available in the
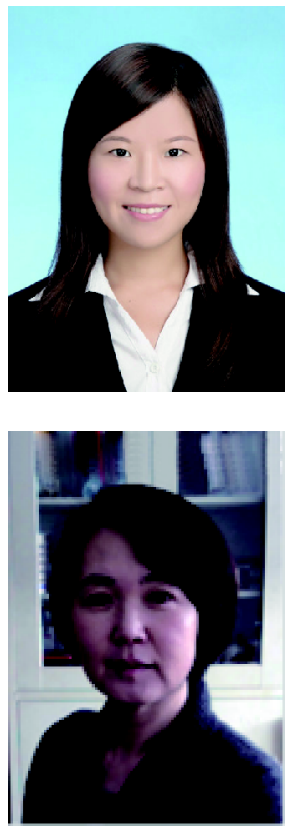

Xiaoli Jia received her BSc degree in chemistry from East China Normal University in 2014. She joined Prof. Che's group as a $\mathrm{PhD}$ candidate in 2014. Her research interests focus on the design and synthesis of hierarchical zeolitic materials.

Shunai Che is a professor in the Department of Chemistry, School of Chemistry and Chemical Engineering, Shanghai Jiao Tong University. She received her PhD degree from Yokohama National University. She was a guest researcher at Saitama University and worked as a postdoctoral fellow at Yokohama National University. Her research interests encompass the development of chiral inorganic materials and porous materials with novel structures and functions in view of applications in optical devices and heterogeneous catalysis.

\section{无添加剂体系合成具有共生结构的介孔FAU沸石}

贾晓利 ${ }^{1}$, 韩璐 ${ }^{1}$,马延航 ${ }^{2}$, 车顺爱 ${ }^{*}$

摘要 本文用无添加剂体系合成了具有共生结构的介孔FAU沸石. 该材料具有由约 50 纳米厚度的纳米片堆积形成的花状形貌, 而且具有两 种孔道体系: 沸石骨架本身的微孔和存在于纳米片内部的晶间介孔. 通过对合成条件精确的控制以及对反应物比例的䇥选, 分别合成了介 孔X型(硅铝比<1.5)和Y型(硅铝比>1.5)沸石. 温和的温度以及高碱度使得在成核初期发生结晶-溶解-重结晶过程是形成介孔FAU沸石的关 键条件. 该合成体系用简单和低成本的方法在FAU沸石中引入介孔, 有望突破沸石在大分子催化中的限制, 将有可能应用于工业化生产. 